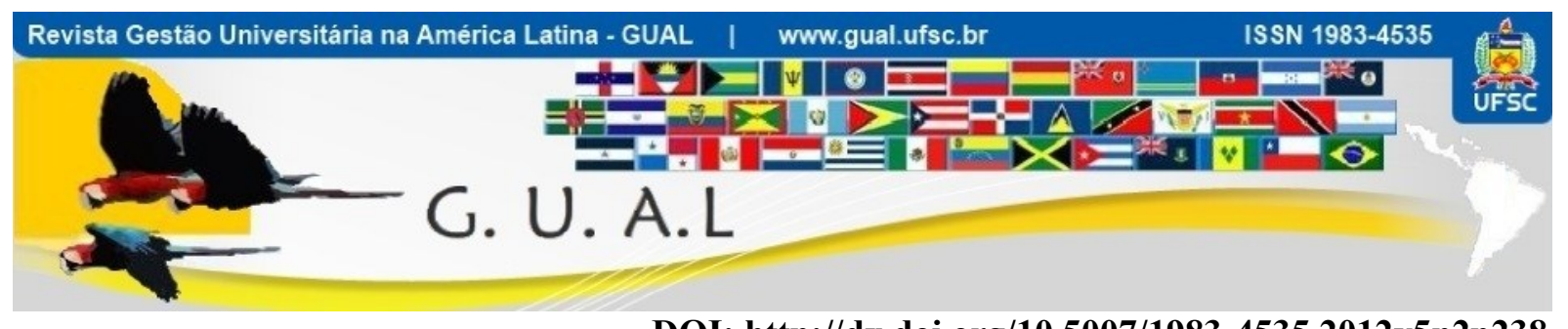

DOI: http://dx.doi.org/10.5007/1983-4535.2012v5n2p238

\title{
ANÁLISE DAS CAUSAS DA EVASÃO ESCOLAR DO CURSO TÉCNICO DE INFORMÁTICA EM UMA FACULDADE DE TECNOLOGIA DE FLORIANÓPOLIS
}

\section{ANALYSIS OF THE CAUSES OF EVASION SCHOOL OF THE COURSE COMPUTER TECHNICAL IN A COLLEGE OF TECHNOLOGY OF FLORIANÓPOLIS}

Recebido em 17/outubro/2011

Aprovado em 04/junho/2012

Sistema de Avaliação: Double Blind Review

Esta obra está sob uma Licença Creative Commons Atribuição-Uso. 


\title{
RESUMO
}

Este trabalho refere-se a uma pesquisa que iniciou em outubro de 2009 e finalizou em setembro de 2011. As informações coletadas foram retiradas de uma faculdade de tecnologia de Florianópolis por meio de um levantamento de dados dos documentos da instituição de ensino, com o intuito de verificar as causas da evasão do curso técnico de Informática dessa faculdade. O objetivo deste trabalho foi analisar os principais fatores que contribuíram para a evasão escolar dos alunos ingressos nos anos de 2006 a 2009. Foi utilizada, para a coleta de dados, a pesquisa documental, tendo como base as informações retiradas do sistema de gestão da instituição. Este trabalho constituiu-se no primeiro levantamento de dados sobre as principais causas de evasão do curso técnico nessa faculdade, permitindo que, através da análise dos dados, fosse possível buscar estratégias para enfrentar o problema, com isso possibilitando a diminuição no índice de evasão no referido curso.

Palavras-chave: Educação profissional. Evasão escolar. Estratégias.

\begin{abstract}
This paper refers to research that began in October 2009 and ended in September 2011. The information collections were taken from a Faculty of Technology Florianópolis through a data collection of documents of education institution in order to ascertain the causes of Evasion Course Faculty of Technical Informatics. The aim of this study was to analyze the main factors that contributed to the dropout of former students in the years 2006 to 2009. Was used to collect data to document research based on information taken from the management system of the institution. This work constituted the first data collection on the main causes of this evasion of the undergraduate college, by allowing analysis of the data it was possible to develop strategies to address the problem, thus enabling a reduction in the dropout rate in that course.
\end{abstract}

Keywords: Vocational education. Truancy. Strategies. 


\section{ANÁLISE DAS CAUSAS DA EVASÃO ESCOLAR DO CURSO TÉCNICO DE INFORMÁTICA EM \\ UMA FACULDADE DE TECNOLOGIA DE FLORIANÓPOLIS \\ DOI: http://dx.doi.org/10.5007/1983-4535.2012v5n2p238}

\section{INTRODUÇÃO}

Neste artigo, discutem-se as principais causas da evasão escolar no curso técnico de Informática de uma faculdade de tecnologia de Florianópolis. A partir da pesquisa documental que foi realizada na instituição, obtiveram-se os dados referentes à quantidade de alunos ingressos, evadidos e concluintes nas turmas de 2006 a 2009. Tal investigação envolveu a coleta de dados através do sistema de gestão da faculdade, permitindo resgatar as informações necessárias de todos os alunos ingressos no período selecionado para a pesquisa.

Percebe-se, através da pesquisa bibliográfica, que a evasão escolar de curso técnicos em outros países do mundo é um tema de estudo bastante frequente. Em nosso país, a realidade é oposta: não existem muitos estudos sobre o tema. Conforme Machado e Moreira (2009, p. 3):

\footnotetext{
A ausência de estudos sobre o tema pode estar relacionada ao fato de que o processo de democratização da escola técnica de nível médio no Brasil apenas se iniciou. E se a democratização do ensino significa o acesso dos estudantes à escola e a sua permanência nos estudos, a crise em um desses dois termos se mostra um problema. A evasão se refere justamente aos fatores que levam o estudante a não permanecer nos estudos. É, portanto, uma questão relacionada à democratização da escola técnica no país.
}

Visando à participação mais rápida no mercado de trabalho, há uma crescente procura pelo curso técnico de Informática na instituição ora analisada. Muitas empresas de tecnologia de Florianópolis buscam essa faculdade para a contratação de mão de obra especializada. Constata-se, ainda, que o mercado de tecnologia de Florianópolis é amplo e diversificado, com muitas opções disponíveis para o profissional de informática. Contudo, mesmo com essa realidade, percebe-se que muitos alunos abandonam o curso antes de se formarem.

O interesse neste artigo surgiu pelo trabalho realizado na coordenação pedagógica da instituição, onde se notou a ocorrência de um grande percentual de alunos evadidos e não concluintes do curso técnico de Informática. Assim, este estudo tem como objetivo geral analisar os principais fatores que contribuíram para a evasão escolar do curso técnico. Para isso, foi realizado um levantamento das turmas do curso técnico de informática no período de 2006 a 2009, para identificar-se a quantidade de evadidos por turma. O perfil do aluno evadido foi analisado e, com isso, obteve-se mais clareza quanto aos principais motivos da evasão. 


\section{ANÁLISE DAS CAUSAS DA EVASÃO ESCOLAR DO CURSO TÉCNICO DE INFORMÁTICA EM \\ UMA FACULDADE DE TECNOLOGIA DE FLORIANÓPOLIS \\ DOI: http://dx.doi.org/10.5007/1983-4535.2012v5n2p238}

Com essas informações pretende-se definir estratégias e ações para prevenir a evasão escolar. Nesse sentido, detectam-se fatores que contribuiriam para uma discussão mais ampla a respeito da evasão escolar no referido curso.

\section{EDUCAÇÃO E SOCIEDADE}

$\mathrm{Na}$ formação da sociedade, a educação faz parte da vida do homem, visando à construção e reconstrução do conhecimento. Portanto, é o fator principal da vida em sociedade. Na definição do dicionário Caldas Aulete (2008, p. 380), "Educação [é] ação ou resultado de educar-se. A educação é fundamental para o desenvolvimento da capacidade física, moral e intelectual do ser humano visando à integração social".

Segundo Pimenta e Anastasiou (2002 apud CANTO; RASCHE, 2008, p. 86),

[...] pode-se afirmar que a educação é um processo "natural" que ocorre na sociedade humana pela ação de seus agentes sociais como um todo, configurando uma sociedade pedagógica. Algumas instituições se incumbiram da tarefa de "desnaturalizar" a educação, assumindo a responsabilidade de desenvolvê-la sistemática e intencionalmente em vista de determinadas finalidades. São os sistemas educativos que envolvem as escolas e seus desdobramentos em órgãos dos sistemas de ensino, em instituições de formação profissionais, de pesquisa, de desenvolvimento de tecnologia e de todo o arcabouço do pensamento e das idéias.

A educação é um espaço de interação social e objetiva fortificar e capacitar o ser humano para a apropriação e a transmissão do conhecimento. Nas palavras de Silva (2002 apud MORAES; THEÓPHILO, 2008, p. 3), “A educação está situada no coração do desenvolvimento do ser humano, fazendo frutificar os seus talentos e potencialidades criativas, o que implica a capacidade de cada um em responsabilizar-se pela realização do seu projeto pessoal".

Precisamos entender como se faz o processo de ensinar para entendermos os motivos pelos quais um aluno procura um determinado curso para sua capacitação e depois abandona essa escolha. Com isso, pode-se desenvolver situações e relações de qualidade que permitam ao aluno o desenvolvimento intelectual para a construção do conhecimento, tornando-o crítico, participativo e reflexivo de suas dificuldades. 


\section{EVASÃO ESCOLAR}

A evasão escolar é um tema atual e que preocupa muitos profissionais na área de educação e nas instituições de ensino. Através da leitura de textos, artigos e teses, percebe-se que os estudos estão voltados para a evasão escolar do ensino fundamental e médio. Existem, portanto, poucos estudos voltados para o ensino técnico e superior.

Quantos aos estudos sobre o ensino básico, os principais motivos da evasão mencionados são problemas socioeconômicos e a inadequação do sistema educacional. Para os cursos superiores, os problemas apontados para o abandono escolar são: trabalho, insatisfação com o curso escolhido, doença grave ou morte e transferência de domicílio.

Muitos alunos têm que dividir seu tempo entre a faculdade e o trabalho, e são vencidos pelo cansaço, optando pelo dinheiro necessário à sobrevivência. Outros são afetados com o problema da moradia, tendo que arcar com o alto preço dos aluguéis ou das passagens, sem falar no tempo despendido por aqueles que moram longe da escola. Isso leva à evasão universitária e ao baixo rendimento dos alunos. (KAFURI; RAMON, 1985 apud MORAES; THEÓPHILO, 2008, p. 5).

Segundo Santana et al. (1996 apud MORAES; THEÓPHILO, 2008, p. 4), a evasão escolar é um dos maiores e mais preocupantes desafios do sistema educacional, pois é fator de desequilíbrio, desarmonia e desajustes dos objetivos educacionais pretendidos. $\mathrm{O}$ autor acusa a escola, responsável pelo processo de educação formal, de não motivar os alunos e não atrair professores com melhores qualificações, oferecendo, assim, uma aprendizagem deficitária.

Conforme aponta Biazus (2005 apud MORAES; THEÓPHILO, 2008, p. 6),

Por mais que se pesquisem os fatores determinantes da evasão discente, percebe-se que os mesmos se manifestam em graus distintos nos mais variados cursos das IES - Instituições de Ensino Superior, não havendo uma lógica uniforme que possa explicar homogeneidade à sua ocorrência no conjunto dos cursos, pois normalmente esses fatores estão relacionados às características individuais, fatores internos e fatores externos às IES. [...] As causas internas são referentes aos recursos humanos, a aspectos didático-pedagógicos e à infraestrutura. Já as causas externas são ligadas a aspectos sócio-políticoeconômicos e as causas relacionadas ao aluno são aquelas referentes à vocação e a outros problemas de ordem pessoal.

Por meio desse cenário, percebe-se que ter os melhores docentes em cada área para a qualificação dos estudantes de um curso não é sinônimo de permanência na instituição. Se considerarmos que, num sistema educacional que adota como metodologia diferenciada a avaliação por competências, na qual, o aluno é avaliado através de conhecimentos, 


\section{ANÁLISE DAS CAUSAS DA EVASÃO ESCOLAR DO CURSO TÉCNICO DE INFORMÁTICA EM \\ UMA FACULDADE DE TECNOLOGIA DE FLORIANÓPOLIS \\ DOI: http://dx.doi.org/10.5007/1983-4535.2012v5n2p238}

habilidades e atitudes desenvolvidas ao longo do processo de aprendizagem. Poderíamos verificar que isto contribuiria para o aumento da desistência no curso, pois o impacto da ruptura com o sistema educacional tradicional e com a mera memorização de conteúdo para mergulhar no cenário de apreensão ou não de conhecimentos. Esse é um fator relevante e que precisa ser pensado, principalmente na IES pesquisada.

\section{METODOLOGIA DA PESQUISA}

Iniciou-se o trabalho de pesquisa em julho de 2009. Na primeira etapa do projeto fezse necessário realizar um levantamento através de leituras e análise de material bibliográfico sobre o tema fracasso/evasão escolar. Essa pesquisa foi realizada em periódicos, teses, dissertações e livros publicados no Brasil.

Num segundo momento, realizou-se uma pesquisa documental através do sistema de gestão da faculdade, possibilitando formar a listagem da população de estudo. As listagens das turmas possibilitaram a coleta de dados para a verificação da situação de cada aluno.

Após conhecidas as primeiras informações, fez-se necessário levantar a quantidade de alunos concluintes, de evadidos e em situação regular na faculdade. Optou-se por verificar a situação de registro de cada aluno, pois a partir de 2007 a instituição de ensino começou a realizar um acompanhamento regular da situação dos alunos, agrupados por turma.

Por último, mas não menos importante, com o levantamento dos dados referentes à evasão pôde-se identificar quais foram as estratégias tomadas pela instituição para evitar o problema de evasão do curso técnico.

\section{ANÁLISE DOS DADOS OBTIDOS}

Apresentam-se a seguir os resultados obtidos através da pesquisa realizada no sistema de gestão da unidade. A decisão para pesquisar esse assunto ocorreu devido à inserção da pesquisadora como funcionária na instituição mencionada, onde acompanhou a evasão dos alunos do curso mencionado anteriormente.

Os primeiros dados levantados foram para verificar se no curso técnico de Informática havia mais alunos do sexo masculino ou do feminino (gráfico 1). 


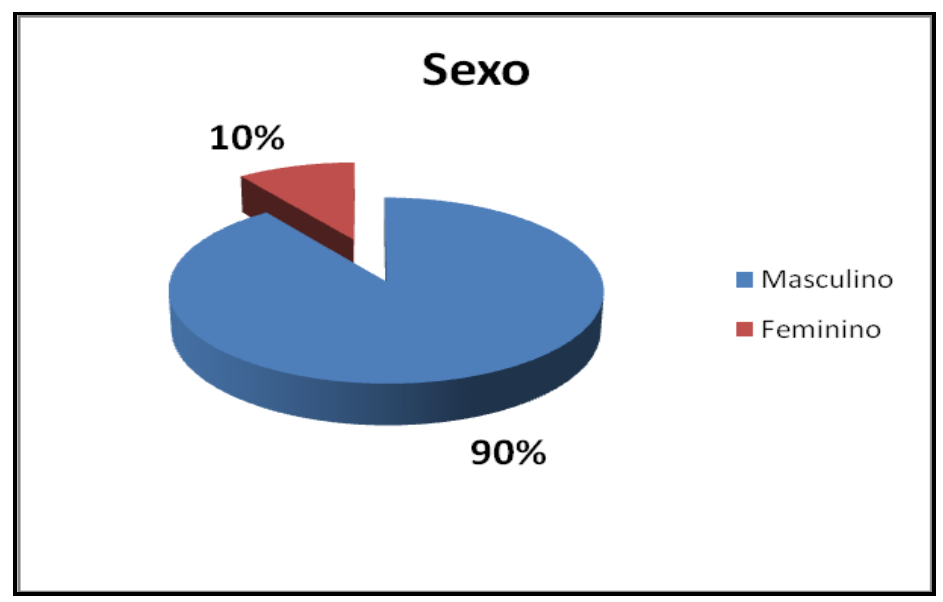

Gráfico 1 Sexo dos alunos

Fonte: Elaborado pela autora.

Observou-se, após a coleta de dados, que a quantidade de alunos do sexo masculino é maior $(90 \%)$. Isso ocorre, provavelmente, porque na área de tecnologia a concentração de pessoas do sexo masculino é historicamente maior. Percebeu-se, após essa etapa, a necessidade de verificarmos a quantidade de alunas por turma, conforme mostra o quadro 1.

\begin{tabular}{|c|c|c|c|c|}
\hline \multicolumn{5}{|c|}{ Sexo } \\
\hline Turma & Masculino & $\%$ Masculino & Feminino & $\%$ Feminino \\
\hline $2006 / 1$ & 13 & $76 \%$ & 4 & $24 \%$ \\
\hline $2006 / 2$ & 30 & $100 \%$ & 0 & $0 \%$ \\
\hline $2007 / 1$ & 31 & $94 \%$ & 2 & $6 \%$ \\
\hline $2007 / 2$ & 32 & $94 \%$ & 2 & $6 \%$ \\
\hline $2007 / 2 \mathrm{M}$ & 28 & $82 \%$ & 6 & $18 \%$ \\
\hline $2008 / 1$ & 28 & $90 \%$ & 3 & $10 \%$ \\
\hline $2008 / 1 / \mathrm{M}$ & 27 & $87 \%$ & 4 & $13 \%$ \\
\hline $2008 / 2$ & 30 & $91 \%$ & 3 & $9 \%$ \\
\hline $2009 / 1$ & 29 & $88 \%$ & 4 & $12 \%$ \\
\hline $2009 / 2$ & 30 & $91 \%$ & 3 & $9 \%$ \\
\hline Total & 278 & $90 \%$ & 31 & $10 \%$ \\
\hline Total Geral & \multicolumn{5}{|c|}{309} \\
\hline
\end{tabular}

Quadro 1 Distribuição por sexo

Fonte: Elaborado pela autora.

Através do quadro 1 constatamos que a segunda turma analisada não possuía nenhum aluno do sexo feminino, enquanto nas demais turmas os números ficavam entre 2 e 4 . Com a ampliação e divulgação da área de informática na região da Grande Florianópolis, no entanto, aos poucos as mulheres estão buscando com mais intensidade os cursos voltados para a área tecnológica. Outro fator relevante diz respeito à faixa etária dos alunos que buscam os cursos 


\section{ANÁLISE DAS CAUSAS DA EVASÃO ESCOLAR DO CURSO TÉCNICO DE INFORMÁTICA EM \\ UMA FACULDADE DE TECNOLOGIA DE FLORIANÓPOLIS \\ DOI: http://dx.doi.org/10.5007/1983-4535.2012v5n2p238}

técnicos, conforme mostra o gráfico 2 .

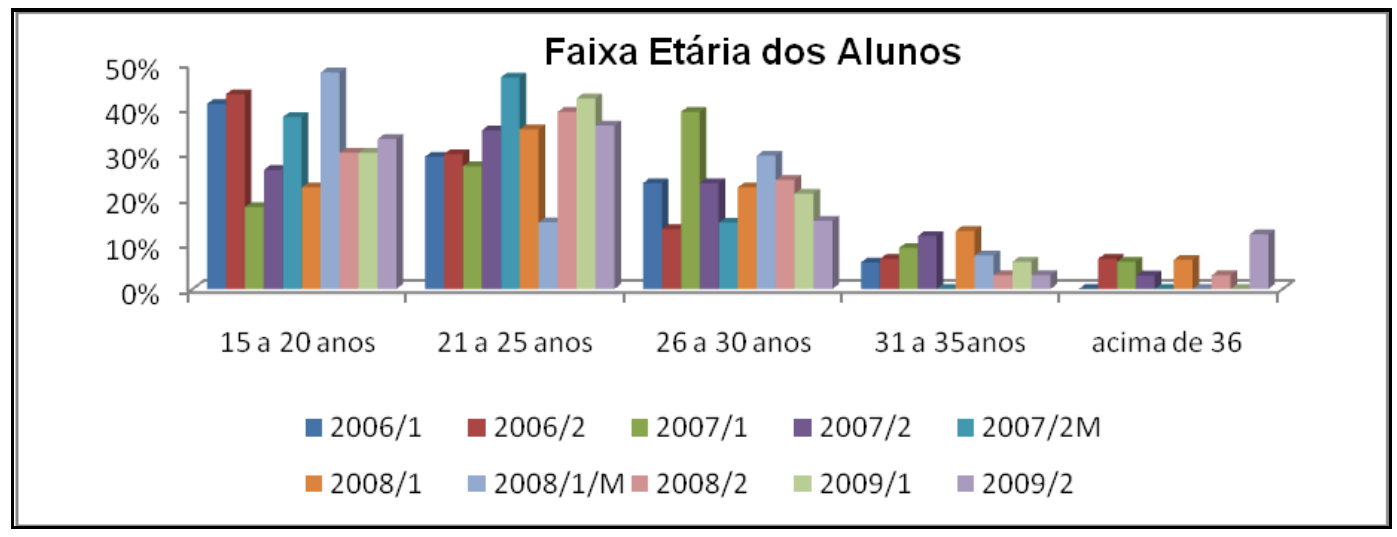

Gráfico 2 Faixa etária dos alunos

Fonte: Elaborado pela autora.

Verifica-se que a maioria dos alunos do curso concentra-se na faixa etária de 15 a 25 anos. Outro fato importante é que o percentual de pessoas acima de 31 anos é baixo, se comparado à faixa etária de 15 a 25 anos. Isso comprova que o mercado de trabalho na área de informática busca pessoas jovens, concentrando-se até os 30 anos de idade. Observa-se, também, que pessoas com idade superior a 36 anos não estão realizando cursos na área de TI.

No gráfico 3 apresentamos, por turma, o número de alunos ingressantes.

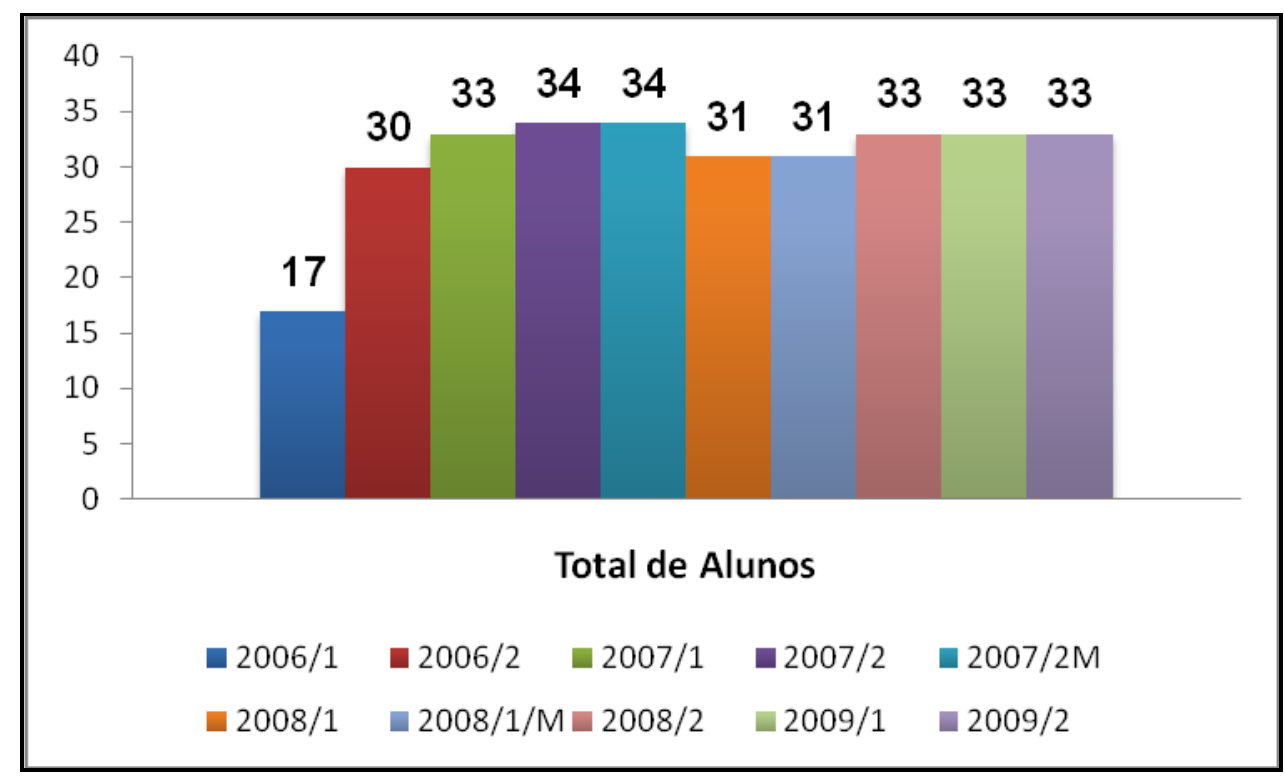

Gráfico 3 Alunos por turma

Fonte: Elaborado pela autora.

Nota-se que a primeira turma (ano 2006, primeiro semestre) contou com poucos alunos iniciando, enquanto as demais apresentam praticamente o mesmo número de alunos ingressantes nos anos e semestres subsequentes. 


\section{ANÁLISE DAS CAUSAS DA EVASÃO ESCOLAR DO CURSO TÉCNICO DE INFORMÁTICA EM UMA FACULDADE DE TECNOLOGIA DE FLORIANÓPOLIS \\ DOI: http://dx.doi.org/10.5007/1983-4535.2012v5n2p238}

O próximo gráfico (gráfico 4) aponta o índice de alunos evadidos por turma. É pertinente ressaltar que, para a instituição pesquisada, alunos evadidos são os que não formalizaram a desistência na secretaria escolar.

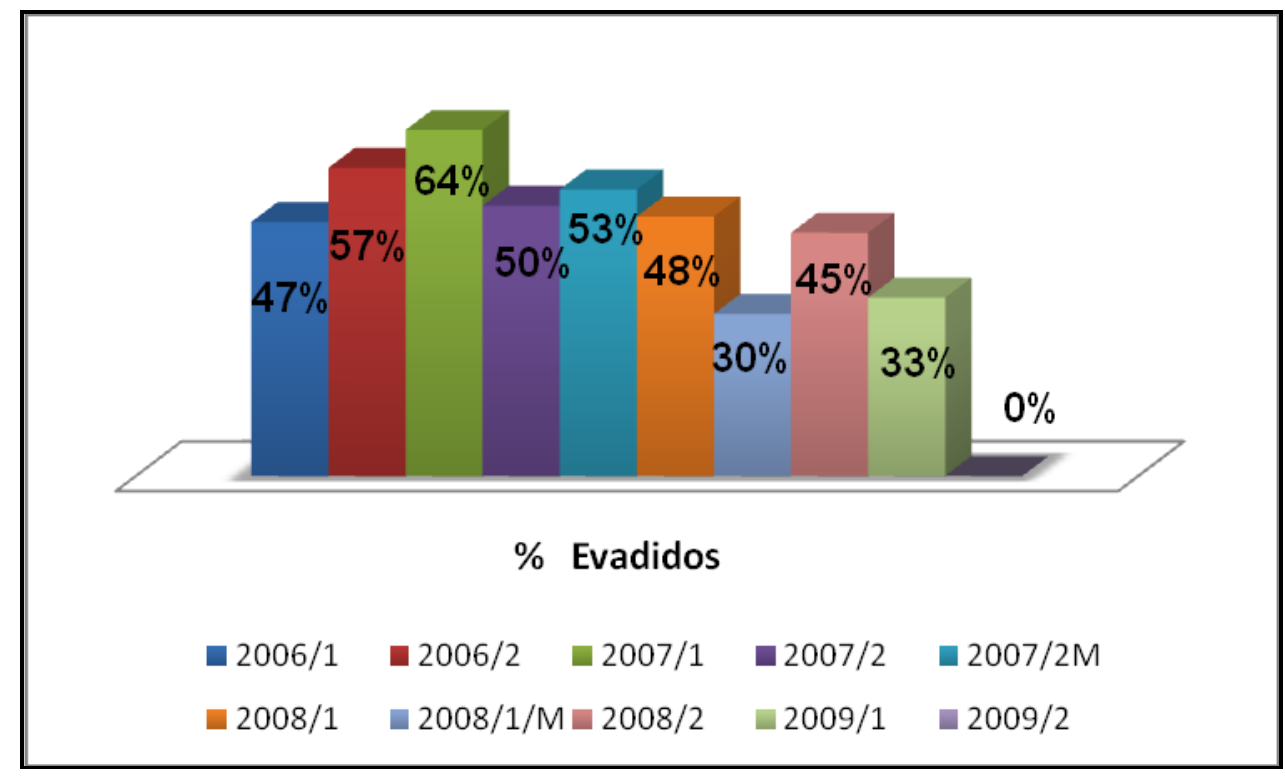

Gráfico 4 Alunos evadidos

Fonte: Elaborado pela autora.

Os dados analisados indicam que o índice de alunos evadidos é alto. Após as ações realizadas pela equipe da instituição a partir de 2007, o índice de evasão por turma não ultrapassou os 50\%. Comparando as turmas 2009/1 e 2009/2, o índice de evasão é inferior a $35 \%$.

No gráfico 5 é apresentada a quantidade de alunos desistentes por turma. Alunos desistentes, para a instituição, são os que formalizaram sua desistência do curso na secretaria escolar.

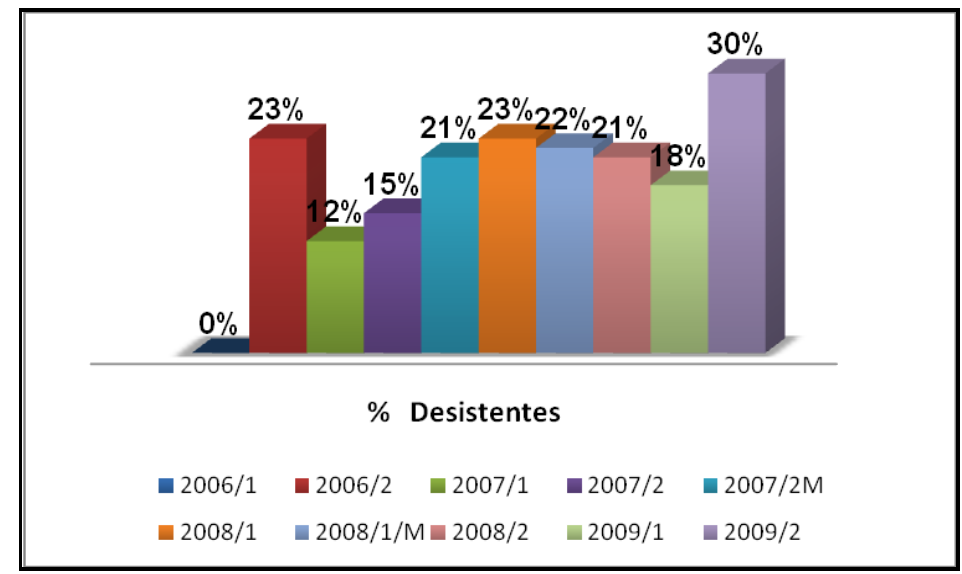

Gráfico 5 Alunos desistentes Fonte: Elaborado pela autora. 


\section{ANÁLISE DAS CAUSAS DA EVASÃO ESCOLAR DO CURSO TÉCNICO DE INFORMÁTICA EM \\ UMA FACULDADE DE TECNOLOGIA DE FLORIANÓPOLIS \\ DOI: http://dx.doi.org/10.5007/1983-4535.2012v5n2p238}

Através do acompanhamento constante das turmas do curso técnico, consegue-se perceber que houve um incremento no número de alunos que formalizaram sua desistência no curso. Com a atuação do coordenador do curso e da coordenação pedagógica no acompanhamento frequente do desempenho e das faltas dos alunos, percebe-se que o índice de desistências formalizadas aumentou, comparando-se a turma 2006/1 à de 2009/2.

Com o acompanhamento constante, tornou-se mais fácil identificar quais são os principais motivos da desistência do curso técnico, conforme mostra o gráfico 6 .

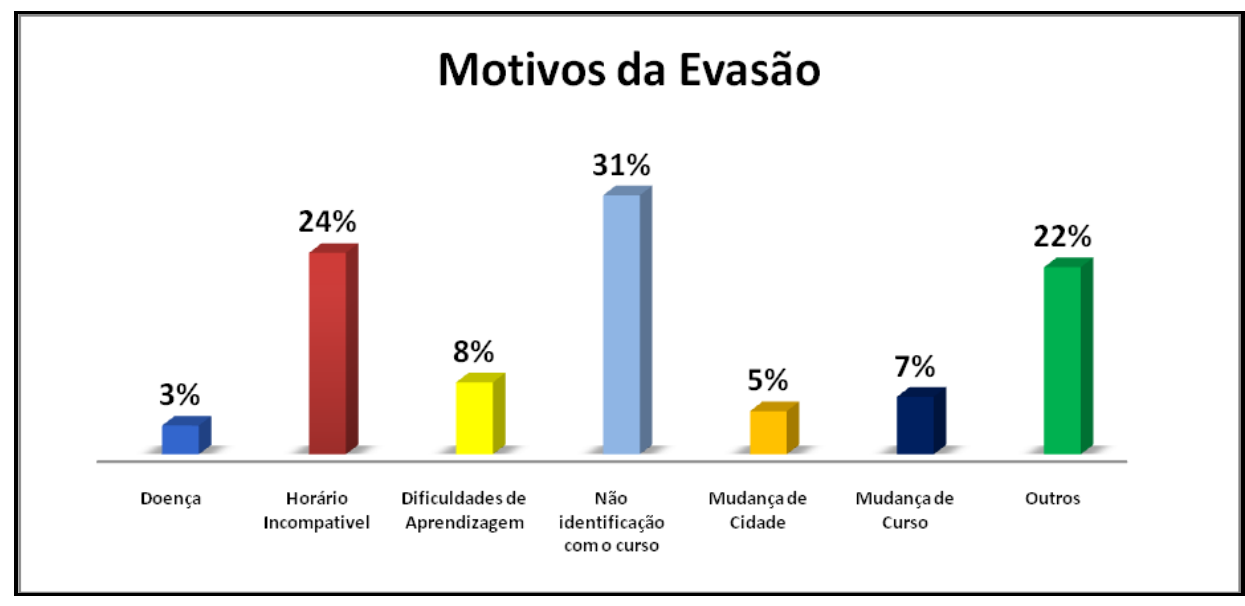

Gráfico 6 Motivos de evasão

Fonte: Elaborado pela autora.

Percebe-se, com a análise do gráfico, que a maioria das desistências é pela não identificação com o curso. Muitos alunos desistentes apontaram também que tinham dificuldades para se dedicar ao curso, pois a maioria precisava trabalhar na parte da manhã e acabava sem tempo para acompanhar as disciplinas.

Alguns alunos apontaram, ainda, como motivo de desistência do curso, a falta de nivelamento da turma, pois alguns apresentam rendimento abaixo dos demais, prejudicando a evolução do aprendizado. Ficou evidente, também, que alguns deles abandonaram o curso para prepararem-se para o vestibular, enquanto outros sequer mencionaram o motivo da desistência.

A última análise desta pesquisa aponta a quantidade de alunos concluintes por turma (gráfico 7). Observa-se, com estes dados, que, após as ações tomadas pela equipe técnica da instituição de ensino, o percentual de alunos concluintes aumentou. 


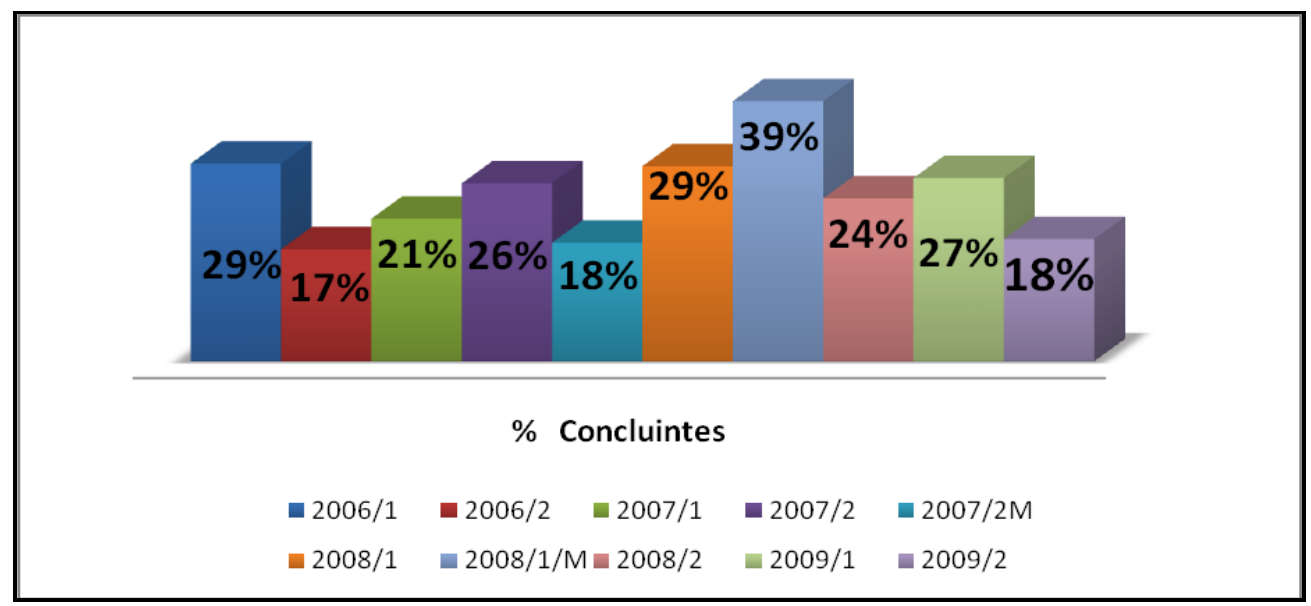

Gráfico 7 Concluintes por turma

Fonte: Elaborado pela autora.

Nas turmas 2009/1 e 2009/2, tivemos no total vinte cinco (25) alunos que concluíram o curso. Observamos que após o acompanhamento das turmas pela equipe multidisciplinar da instituição, os alunos, que chegam no $4^{\circ}$ semestre finalizam o curso.

\section{MEDIDAS ADOTADAS NA INSTITUIÇÃO}

Trabalhar no setor da coordenação pedagógica possibilitou à pesquisadora a percepção de que não existiam estratégias definidas para acompanhar a situação de cada turma, bem como a quantidade de alunos concluintes e evadidos do curso técnico e superior.

Para mudar essa realidade e verificar quais os motivos da desistência dos cursos, foram criadas algumas estratégias para o acompanhamento dos alunos. Dentre elas, destacamse as seguintes:

- reuniões mensais para discussão e verificação da situação de cada turma, com vistas à análise da quantidade de alunos evadidos;

- criação de uma planilha, por turma, de acompanhamento de faltas;

- contato com os alunos com faltas consecutivas em duas semanas, feito pelo coordenador do curso;

- conversa entre o aluno, o coordenador do curso e a coordenação pedagógica, sempre que há a manifestação de desistência do curso;

- identificação do problema e estabelecimento de estratégias para que o aluno não abandone o curso;

- acompanhamento constante dos alunos que estão na fase final do curso, na etapa de elaboração e entrega do relatório final de estágio, com o intuito de que estes consigam concluir o curso.

Ao comparar-se a evasão dos cursos técnicos com a dos cursos superiores, percebia-se que o índice de abandono de alunos do técnico era maior, o que motivou o trabalho 


\section{ANÁLISE DAS CAUSAS DA EVASÃO ESCOLAR DO CURSO TÉCNICO DE INFORMÁTICA EM \\ UMA FACULDADE DE TECNOLOGIA DE FLORIANÓPOLIS \\ DOI: http://dx.doi.org/10.5007/1983-4535.2012v5n2p238}

desenvolvido com esse nível de ensino. Ficou claro, portanto, que esse assunto merecia um estudo mais detalhado, para que pudéssemos visualizar os motivos e, a partir daí, programar as estratégias de acompanhamento do fenômeno.

Observou-se, através do acompanhamento das turmas, que até o ano de 2008 não havia nenhum aluno concluinte do curso técnico de Informática, e que, após algumas ações da equipe formada pelo coordenador de curso e pela coordenação pedagógica, no ano de 2009, 30 alunos concluíram o curso técnico; na turma de 2011/1, foram 87 concluintes, na turma 2011/2, foram 25 concluintes, na turma 2012/1 foram 14 concluintes.

Pela a análise dos gráficos percebe-se o alto índice de alunos evadidos nas primeiras turmas do curso. No entanto, hoje o que acontece é que o aluno desistente formaliza sua situação na secretaria escolar. Assim, a instituição de ensino consegue conversar com o aluno e verificar os reais motivos da desistência.

É importante destacar que o contato com os discentes ao longo desse processo foi fundamental, pois torna-se possível fazer um acompanhamento das atividades pendentes, orientar os alunos e encaminhá-los para o desenvolvimento do relatório final de estágio e, consequentemente, para a conclusão do curso.

Percebe-se mais nitidamente, com uma vivência na instituição, que a necessidade de criarem-se diversas estratégias para manter os alunos num curso são necessárias. Ações devem ser criadas e mantidas para atender às mais variadas necessidades dos alunos. Envolver os docentes é outro ponto fundamental, principalmente criando-se estratégias que-os mantenham no curso. O enriquecimento extraescolar, a educação orientada, a capacitação dos professores, o aprendizado individualizado e a orientação para o mercado de trabalho são alguns dos indicadores que precisam ser desenvolvidos junto aos discentes para nortear seu caminho.

\section{CONSIDERAÇÕES FINAIS}

Finalizando, percebe-se que os desafios das instituições de ensino para verificar quais são as principais causas de evasão não são simples. É necessário que exista uma equipe multidisciplinar, com profissionais responsáveis pela criação de estratégias e de ações para combater esse problema.

$\mathrm{Na}$ instituição, a partir no momento em que a equipe técnica percebeu que deveria trabalhar e traçar estratégias para combater o alto índice de evasão no curso técnico de 
Informática, ficou claro que os fatores que causavam a evasão no curso ainda não estavam definidos.

As ações implantadas pela equipe iniciaram no final de 2007 e contaram com estratégias para a verificação das principais dificuldades enfrentadas pelos alunos em sala de aula. Atualmente existe um acompanhamento do desempenho escolar do aluno e um controle quinzenal de faltas. $\mathrm{O}$ coordenador do curso é peça fundamental nas ações estabelecidas, pois tem acompanhamento constante com os discentes e com os docentes. Algumas vitórias foram conquistadas no monitoramento constante dos alunos, mas necessita-se de empenho da equipe envolvida na tarefa, pois é difícil perceber o que leva um aluno a desistir do curso.

Entende-se que o fundamental para o sucesso das instituições de ensino é a manutenção e a conclusão de seus discentes nos cursos escolhidos. Para que isso ocorra, a equipe técnica deve criar estratégias e buscar a constante atualização de ações para trabalhar a questão da evasão escolar.

Conclui-se que os estudos referentes à evasão contribuem para conhecermos as diversas causas do problema, e que só assim podemos traçar objetivos e estratégias para lidar com a temática dentro da faculdade. Não basta apenas conhecer as causas da evasão; é necessária a discussão dentro dos centros de ensino para a melhoria da educação e, consequentemente, a permanência do aluno na sala de aula.

\section{REFERÊNCIAS}

AULETE, F. J. Dicionário Caldas Aulete da língua portuguesa: edição de bolso. 2. ed. Rio de Janeiro: Lexikon; Porto Alegre: L\&PM, 2007.

CANTO, Cleunisse R. L.; RASCHE, Francisca. Metodologia do ensino superior. Florianópolis: SENAI/SC Florianópolis, 2008.

DELAGE, Rosângela. Evasão escolar: o que fazer? Abceducatio: a revista da educação, São Paulo, v. 4, n. 25, p. 6-7, jun. 2003.

\section{MACHADO, Marcela R. L.; MOREIRA, Priscila R. Educação profissional no Brasil,} evasão escolar e transição para o mundo do trabalho. Disponível em: <www.senept.cefetmg.br/galerias/.../TerxaTema3Poster9.pdf>. Acesso em: 22 jul. 2009.

MORAES, Júlia de Oliveira de; THEÓPHILO, Carlos R.. Evasão no ensino superior: estudo dos fatores causadores da evasão no Curso de Ciências Contábeis da Universidade Estadual de Montes Claros - UNIMONTES. Disponível em:

<www.congressousp.fipecafi.org/artigos32006/370>. Acesso em: jan. 2010. 